\title{
Conceptual Framework of Lean Ergonomics for Assembly Process: PDCA Approach
}

\author{
Ahmad Nawawi Mohd Amin ${ }^{l}$, Wan Hasrulnizzam Wan Mahmood ${ }^{1,2}$, Seri Rahayu Kamat ${ }^{l}$, Ilyana Abdullah ${ }^{l}$ \\ ${ }^{1}$ Sustainable and responsive manufacturing research group, Faculty of Manufacturing \\ Engineering, Universiti Teknikal Malaysia Melaka, 76100 Hang Tuah Jaya, Melaka, Malaysia. \\ ${ }^{2}$ Faculty of Engineering Technology, Universiti Teknikal Malaysia Melaka, 76100 Hang Tuah \\ Jaya, Melaka, Malaysia.
}

\begin{abstract}
The purpose of this paper is to prepare a conceptual framework of hybrid lean and ergonomics for assembly manufacturing process based. The research used PDCA approach as a basis in linking the relationship between lean manufacturing and ergonomics. Comprehensive literature review identify the lean ergonomics issues, best practices, and also the way to improve the ergonomic conditions in the workplace, especially those impacting employees on the assembly process. The findings show that the job design strategies for reducing extreme injuries influence by repetitive tasks. Selections of lean tools and technique, human factors analysis and lean performance measure are the key point on the stages of the PDCA conceptual framework for lean ergonomics in working assembly process. This paper also demonstrates by continuous improvement applied between the elimination of waste and increased productivity and the impacts on the ergonomic conditions to carry out operations and consequently by improving the productivity and well-being of its employees based on implementation of PDCA conceptual frameworks.
\end{abstract}

Keywords: Lean Manufacturing, Ergonomics, Assembly process, PDCA

\section{INTRODUCTION}

Lean manufacturing can be define as a dynamic process of change driven by a systematic set of principles and best practices aimed at continuous improvement combining the best features of both mass and craft production [1]. It's aimed to reduce and remove wastes in the production flows from all areas of the stream values [2-3]. Furthermore, lean manufacturing also focused on reducing the cost in organisation's works flow of the production and supply chain which is can delivering the highest quality product on time [4]. It can be utilised as adding value for the production strategy aiming to eliminate waste, with limited resources and effectively to meet the customers need to beat other companies in competitive world [5]. Nevertheless, lean manufacturing can be mapped for the whole process to identify of each step phase with the information of each step effectiveness during production to achieve higher productivity [6].
The advantages in implementing and strengthening the lean manufacturing through a consistent effort can assist the organization to stimulate the best strategy in dealing with the effect of the current economic downturn. It's not only increase the level of competitiveness, but also successfully transforms the manufacturing operations to be more dynamic [7]. This allows manufacturers to control the inventory level, optimise the utilisation of work space, and actively monitors the total manufacturing costs efficiently [8]. Therefore, manufacturers can participate actively in revolutionising the manufacturing operations, primarily on increasing the productivity, improving the performance of manufacturing operations as well as financial performance [9]. Besides that, any production issue can be handled with more efficiency, especially in managing the variety of demands in a competitive market environment [10]. This is crucial, primarily for the manufacturer which produces the product that requires high customisation level, in which a high response rate is mandatory [11].

Corresponding Author: Wan Hasrulnizzam Wan Mahmood, Faculty of Engineering Technology, UTeM, Malaysia, +6062346765 
As a philosophy that is conveyed using a multidimensional approach, lean manufacturing had offered a diversity of techniques and strategies in revolutionising the manufacturing sector to become more competitive. Based on core concepts to eliminate waste and non-value added activities in operations in order to maximise the value to the customer, lean manufacturing is often used as a benchmark in developing the strategy to increase the operational efficiency [12]. The ability to understand appropriately each of the lean manufacturing techniques and strategies had also proven to improve the operational performance in terms of productivity improvement, cost, and quality for several decades since it was first introduced in the early 90's [13]. In fact, the outcomes of lean manufacturing implementation in the continuous improvement activities are also benefiting the manufacturers in achieving the sustainability in manufacturing (manufacturing performance indicators) [14]. Besides, the cost of operations can be significantly reduced, especially when the inventory can be managed and controlled at the minimal level [15].

Ergonomics is a method of designing workstations work practices and flow to accommodate the abilities of employees to achieve and maintain high level employee's productivity [16]. Ergonomics involve design of workplace, equipment machine tool, product, environment and system and take it into consideration of the human's physiological and psychological capabilities and optimising the efficiency of the productivity of work system. Ergonomics related to the design of methods and processes can help eliminate or decrease work related risks as well as improve the quality and productivity [17]. Kamala et al. 2016 [18] describes ergonomics as human factor, is the understanding of interactions of humans and other elements in system and other elements of a system to optimise human being and overall system performance. It is also considers both a social goal and economic goal. The main goal of ergonomics is to develop and implemented the man adaptation techniques, efficiency and safest ways in order to optimize the well-being and thus that would increase the productivity [6].

Manufacturing companies face challenges in handling dynamic customer demands, fluctuating material needs and requirements on sustainability regarding economic, environmental and social aspects. These challenges result in increasingly complex production and process systems, especially regarding assembly process [19]. The assembly processes in the most manufacturing company systems are usually conducted by the employees manually with minor levels of mechanisation because of the high cost of automated assembly operations [20]. The organisations always think and find the way to enhance the productivity and efficiency of the assembly line to eliminate waste from the problems. Numerous publications in the area of machine assembly line found that operating the assembly lines has many unsolved problems that considers the design for assembly processes, and enumerates the components of performance, processes and comparative economics regarding several types of machine assembly systems [21-23]. In addition, Lee et al. [24] have found that the modelling of assembly processes, and their solutions and quality of processes also considered as problems in machine assembly line. The application of the Kaizen approach to enhance the efficiency of assembly processes, thereby boosting productivity, lowering costs, and implementing waste reduction [25]. Villarreal and Alanís, [26], assembly processes, which consider practical aspects of finishing, packaging, and automation, are represented in the machine assembly process. Problems in assembly process states may lead to the employee's safety and health in human factors in terms of ergonomics problem.

The basic conceptual framework is proposed to tackle and identify the problems on the assembly process is based on the PDCA conceptual frameworks. The acronyms is define as P "Plan", D "Do", C "Check" and A "Act" to brings the view of the whole assembly process during working time and conditions to prevent from the lean ergonomics problems for waste elimination. Walther Shewart was designed this conceptual framework known as the Plan-Do-CheckAct standard for Quality Management authority W Edwards Deming [27]. The PDCA conceptual framework is used to support and coordinate daily routine management, general problem solving processes, continuous improvement efforts and also supports in assembly process for product development [28]. PDCA conceptual framework can be as indicator to measure the performance and the best way to understanding and create vision in improving the assembly process [29]. Lean manufacturing has been analyse of the revised process, existing process, and 
subsequent Plan-Do-Check-Assess (PDCA) conceptual framework [30]. PDCA conceptual framework are usually applied for further improvement the future on lean manufacturing implementation [31]. Lean manufacturing implementation is mainly dependent on PDCA for assessment and deployment [32].

Recent studies show that many researchers had tried to improve the integration of ergonomic and lean manufacturing for productivity improvement. Besides, many articles found that hidden wastes in lean manufacturing had significant correlated to the human factors [33-35]. Ergonomics injuries and illnesses such as carpal tunnel syndrome, tendinitis and musculoskeletal disorders (MSDs) rate are increasing which cut across all industries and occupations. In fact, ergonomics issues may lead the negative impact on the employees and psychological strain [36-37]. Ergonomics and production requirements are generally seen as one of factors strongly related to the lean manufacturing process [5]. The study found that ergonomics can give impact either decrease or increase the cost of production on employees health and safety [38-40]. By the relatively higher risk associated with older employees, obesity and uncontrolled blood pressure can drive to additional negative financial impacts to organisation because substantially higher costs for insurance and claims [16]. Attaran and Wargo, [41] also reported progressive organisations use ergonomics in a proactive way to prevent problems can give good return, reduced injury and costs, and also improved quality. However, all this issues can be prevent if development of conceptual framework of hybrid lean manufacturing and ergonomics (lean ergonomics approach) using PDCA conceptual frameworks applied during assembly process. This paper is organised as follows: the research method followed by flow chart lean manufacturing and ergonomics reviews. Next, the general information and production processes on development of conceptual framework integrating lean manufacturing and ergonomics based on PDCA conceptual frameworks. The paper ends with conclusions and recommendations for future research in section 4 .

\section{RESEARCH METHOD}

The research method for the study is divided into two phases. The first phase is focusing on literature review which is identification, analyse and interpretation the information of the study. Identify the key elements to determine the major factors to implement the lean manufacturing and ergonomics. Analysis method, framework, approach, finding and the limitation from the implementation of lean manufacturing and ergonomics in various papers is the main point to get the information's from the literature review. Its primary used to highlight the importance information required and provide a comprehensive background [42]. Basic body of literature review focusing on the implementation of the lean manufacturing and ergonomics was used to summarise the existing research by identifying the related issues [43]. The major factors found that the lean and ergonomics was the key element in this study and may lead to find the suitable or exact tools for the lean ergonomics problems [6]. Analysis and interpretation on the details criterion to obtain further indepth information on the lean ergonomics was done. There are certain information was identified from the implementing the lean ergonomics based on human factor issues. If the elements are not clearly classified based on the major contribution and influenced the lean manufacturing and ergonomics, the revision on the classification categories were carried out. Therefore, only related paper and method to synthesise on existing research to the topics were choose to be discussed to ensure each criteria was accurate and unbiased [44].

The second phase is focusing on development of conceptual frameworks of lean ergonomics approach. The PDCA approaches are used in this study. The information serve as a body of the knowledge in identifying and assessing the benefit obtained from the implementing the lean ergonomics on each key elements found before on the first phase [45] .

\section{DEVELOPMENT OF CONCEPTUAL FRAMEWORK INTEGRATING LEAN MANUFACTURING AND ERGONOMICS}

Its start with plan at the first stage which is assembly process in production and product development that may viewed to job design for the whole process including to the selection of lean tool and technique. Do is the which is mean more about analyse the ergonomic risk factor and also include the selection of lean tool and technique. After that, in the next stage is check, analysis on the human factor analysis can effect to the employees. Act is the last part on stage four, considering lean 
performance measure. Stage 1 until stage 4 is reverse process until the problems settle. In this conceptual framework, it is focusing on the waste eliminates in term of human factor. All the lean tools should be synchronising to the human factors for the employee's safety and comfortable. Figure 1 illustrates the proposed conceptual frameworks based on PDCA's point views.

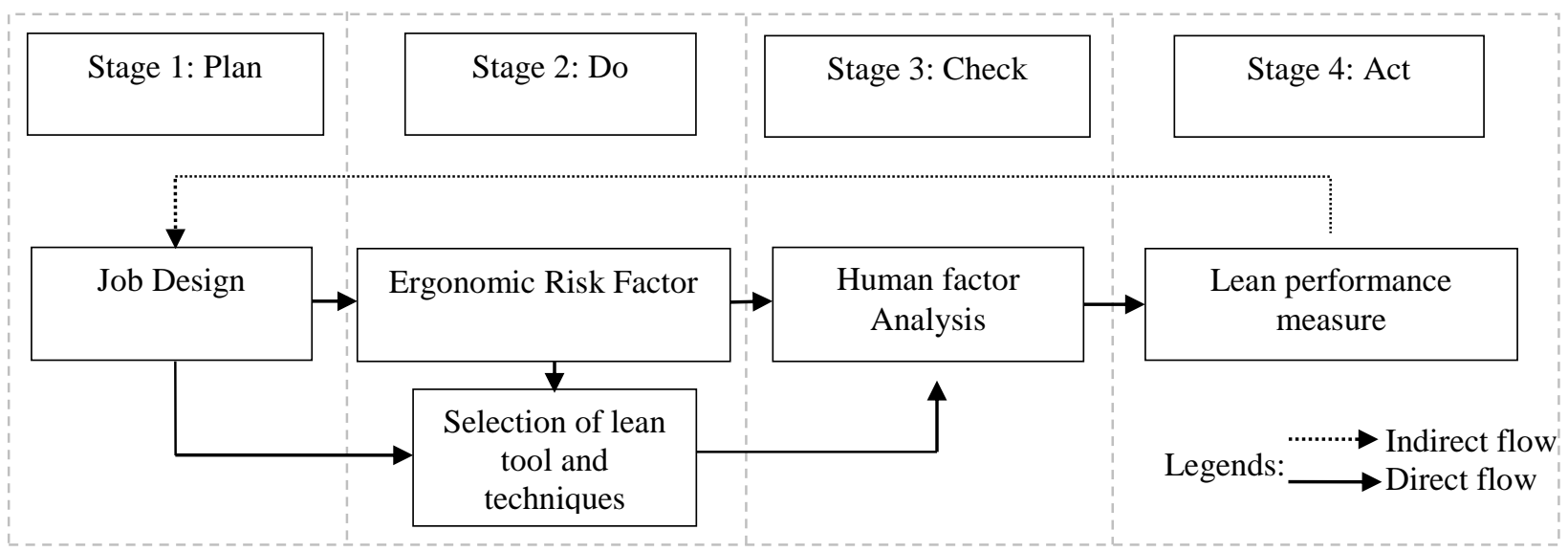

Fig 1 Conceptual Framework of Lean Ergonomics

Stage 1: Plan

The conceptual framework of lean ergonomics start with the organisation planning that creates job design for the whole process on the production line. Job design can be define as fulfil the employee's needs and alternating employees between jobs and tasks (standard of operation)that involve with different skills and responsibility [46]. Job design have been used by organisation to eliminate waste based from preventing on repetitive jobs and objective of production for reduce time and production costs in assembly process [47][49]. Cristini and Pozzoli, [50] pointed job design can be motivate the organisation because job design were part of a lean production system and total quality, focused on the employees requirements with more autonomy during working time in production system. In addition, job design are also commonly recommended to moderate continuous exposure to ergonomics risk factors for MSDs [51-53].

The planning of job design show a discrepancy across each professional sector, which is necessary to the success of the involvement [54]. The successful also depends on employee's training in several jobs and the specific parameters needed in generating more effective job design in prevention and risk control of MSDs [55]. Furthermore, the planning needs to identify organizational demands, physical, and cognitive; to determine exposure levels; and to evaluate and define how the job design planning created.

Guimarães et al. [56] found that employees need to be trained in every job to develop competence and skills and to ensure process and product quality. The planning and implementation also needs to consider on the psychosocial and environmental factors can affect employees health outcomes and the success of the health promotion and prevention programs [57]. In terms of MSDs, alternation strategies for employees between task with different levels of exposure and employees demands may lead to selection of lean tools and technique [58-59]. In this paper, the job designs are pointing to the two parameters in one time which is ergonomics risk factors and selection of lean tools and technique.

The important of the job design to the assembly process is to control/ manage the works flow and also to make sure the employees follow the works specification and safety. Clegg and Spencer, [60] found that the time lags involved in the process can avoided if the planning of job design in assembly process are good. The job design at a workstation influenced the performance of assembly process in terms of support process, manufacturing flexibility, works task efficiency and materials planning [61]. In addition, major impact of the material planning method on assembly process is based on the job design 
and planning [62-63]. To reduce the non value added time in assembly process need to have good job design and planning in lean production [64].

\section{Stage 2: Do}

In the second stage of the frameworks, there are two points of view potential solution proposed which is ergonomic risk factors and selection of lean tool and technique. Ergonomics is interaction between human and machine that refers to the set of disciplines that studies the organization of the works [6]. Previous studies reported, it also can be define as the design of the workplace, environment, equipment, tool, machine, product and system, and also considered the psychological capabilities, physical, biomechanical, physiological, and optimising productivity and effectiveness of work system while assuring the safety, wellbeing of the employer, and health [65]. Ergonomics is aiming not to fit the individual to the task, but to fit the task to the individual in term of human factors. Ergonomics risk factor is any unnatural posture that involves during working position, a not suitable twisted trunk or/ and extended arm position can cause fatigue and reducing also the production output for the company [66]. All the factors can be easier to facing the ergonomic risk factor are climate/ weather (hot and cold) that will change the physical environmental. Jekayinfa, 2007 [67] found that the individual characteristic, age, physical fitness, nutritional, health state, sex and body size also can be the factors and also because of the psychology, economical, technological, cultural and organisational factors also act upon employees working capability and production.

Kleiner \& Webster's, [68] study of ergonomics found the most common injuries that occur (ergonomics risk factor) when poor ergonomics features is Repetitive Motion Injuries/ Repetitive Stress Injuries (RMI/ RSI), MSD and Cumulative Trauma Disorders (CTD), including the tendinitis, lower back pain, carpal tunnel syndrome and similar afflictions that cause from the repeated motion over a period of time, and also can effect to the other body parts in many ways. Bad ergonomics design also can cause the symptom for the bad injuries to the employees and also all the physical problems or injuries lead to inability or limitation to works. This is because of the repetitive stress/motion injuries that only because of the poor ergonomics design. Based on that case, there is the one of the important thing to study on selection of lean tools and ergonomics risk factor. There are numerous reasons justified by the manufacturing industry and described in the literature for using an ergonomics risk factor organizational strategy to get the ideas for using lean manufacturing tools $[49,59]$. The review also presented that study on ergonomics risk factor will improve the musculoskeletal health and job rotation for better right choose of the lean tools [69].

The lack of manufacturing management's methods for solving problems such as project delays because of the ergonomics risk factor may lead the companies find for the solution for cost effectiveness improvement methods and time efficient on the project development cycle [70]. To face the problems, organisation should be find the best of lean manufacturing tools and technique. Lean manufacturing tools and techniques play a vital role in the effective development process in reducing process completion time, hours, design and supply chain management integration, process control, flexibility, environmental sustainability and increased the quality of products [71-74]. In an analysis of lean manufacturing tools and technique, Schweikhart and Dembe [75] found that the successful or failure in any companies is based on the proper prioritisation and the choice of appropriate lean tools. If poor decision making in the lean manufacturing tools implementation for companies improvement and performance cannot be achieved.

A key aspect of lean manufacturing tools and technique is participants from all the employer from the top management to the all employees [76]. Lean manufacturing tools and technique is depending on the choice of the tools suitable to the workers conditions during production process including the workplace, knowledge, type of process, skills and the available resources to prevent from ergonomics risk factors [75, 77]. According to Koay and Sorooshian, [78] and Abdul Rahman et al. [79], right choosing on lean manufacturing tools and technique that based on the employees feelings and conditions can lead to better delivery system and process, environmental sustainability, increasing productivity and safety and health, financial performance and achieved customers requirements. The tools and technique should be appropriate for human factors to prevent waste from workers accident that can lead to injuries, hours claim, sick leave and claim, insurance and etc. 
Eliminating waste in assembly process for improving quality, reducing cost and staying competitive will be increase and achieve when the efficient knowledge about ergonomics risk factors and the lean manufacturing tools and techniques for manpower (employees) implement in the companies. By implement lean tools and techniques, Zhang and Chen, [80] saying that the knowledge creation to become more holistic and efficient management system and lead to improve lean performance for man power in the assembly process and at the same time, the safety of the employees also emphasized. Lean tools and technique supported technical aspects and optimisation of human factors in design of production system especially in assembly process [53, 81]. Using this approach, researchers have been analysed the impact on productivity levels based on the workplace, incorporating lean technique for man power [34, 82-83].

\section{Stage 3: Check}

Research on the lean waste elimination has been mostly saying that educating or practices in personal on knowledge of lean manufacturing can approaching continuous improvement cultures, may lead to change that facilitate ongoing quality improvement [84]. Hamid, [85] identified critical success factors for lean manufacturing, which is eight internal organisational factors and two external factors. The internal organisational factor is top management, training and education, thinking development, employees, working culture, communication, resource and business planning. The external factor is customer focus and government intervention. Much of the lean manufacturing research focused on identifying and evaluating that the top management is the key on success factor either the study was focused on specific countries, big company or organisation and also small medium enterprise (SMEs) [86]. The top management is the checker or examiner for the whole process in the company especially in assembly process to make sure to reduce and eliminate waste in assembly process during production. Similarly, Salonitis and Tsinopoulos, and Zargun and Al-Ashaab [87-88] found that the top management involvement and commitment as critical success factors that required by the leadership for a successful implementation and need to be firm and inspiring, relentless and resilient, demanding and forgiving, focused and flexible. Development of employees and performance in assembly process and other process in company is responsible to the top management, manager, and also respect to each other's including periodic checklist for the employees [89]. Most of the employees give all the commitment to the company if the top management give the good service including the knowledge and practices on safety during works. Based on the management investigation, to educate and train the employees on the principles of lean manufacturing is the one of the important thing [90].

Involvement of the employees in implementing of lean manufacturing is also critical for the success. Ergonomics which mean human factors is the main obstacle in implementing lean manufacturing because employees tend to resist change or backslide to old ways doing things [8]. Therefore, the point successful the lean manufacturing is based on the employee's safety and comfortable to prevent from employee disappears. Smith [39], Vieira et al. [83] and Aqlan, [91] found that from workers interview and questionnaires on the case study analysis of the effect of lean manufacturing on worker safety and health have reported increased health, job satisfaction and job motivation will increase the workers performance and the consequently, can avoid from excessive fatigue and accidental injuries and also worker perceive better working conditions. Increasing the injury will disturbed the lean manufacturing process in the long term, the economic saving from quality, productivity and efficiency improvements pay for the higher cost of employee's compensation claims for medical [92]. Designing the machine that can match to the workers/ operators abilities to achieve maximum safety, comfort and efficiency can improve production and reduce work fatigue [93]. Based on that case, study on ergonomics analysis or human factor analysis are the key to reduce waste value creation in lean manufacturing strategy [5]. Human factors analysis is about employee's suitable posture during working time. Positively impacts on safety and ergonomics issue when repetitive task or job on employees. The organisation should be committing its time and resources for ergonomics or human factor analysis to get positive returns, reduced injury and cost and also improve quality.

There are several ergonomics or human factor analysis assessment tools that can be used that may assist in analysing risk factors during assembly process. Ergonomics Risk Assessment (ERA) is the method used for the ergonomics evaluation risk factors that may 
cause harm for the employees. The main concerns in the ergonomics risk assessment in manufacturing production line are divided into three which are environment, human and machine. The intensive developments of ergonomics in the past few decades have been resulting in numerous different methods for ergonomic assessment and improve working conditions [94]. Variety of ergonomics risk factors can be associated with those three causes. All these risk factors give huge implications to the human. In this review paper, Rapid Upper Limb Assessment (RULA) and Rapid Entire Body Assessment (REBA) are the tools to measuring the ergonomics factors effect. RULA is a method in postural targeting for estimating the risk of work related upper limb disorders while REBA is focusing on the risk of work related entire body disorders estimation. Ansari and Sheikh, [17] in their project applied RULA and REBA as their assessment which successfully specifies that the workers of small scale industry situated at MIDC Wardha (Maharashtra, India) are working above limit. Both assessment gives quick and systematic evaluation of the complete body postural risk to a worker which is these ergonomics tools end up with score mark [95].

\section{Stage 4: Acts}

In last stage of PDCA conceptual framework is act which mean to understanding the best solution in implementation of lean ergonomics approaches. The process will re-do and investigate all over again from the start job design if the lean performance measure shows not give an impact on the assembly process. Lean performance measure is the study suggested that can give advanced level of lean ergonomics implementation and have achieved better operational performance. The importance of lean performance measure on organisation performance is to choose the best solution from implementing lean ergonomics before come out the standard of operational result in assembly process. The lean performance measure based on tools and techniques are widely used for lean ergonomics implementation in the industry [96]. Cua et al. [2] from the research found that 163 plants in Italy, UK, USA, Germany, and Japan observed positive impact on manufacturing performances (quality, cost, flexibility and delivery) when right chosen of lean performance measure were jointly implemented.
The operational performance measure will shows the result on the employee's performance productivity, first pass correct output, and including cost of conversion, inventory, manufacturing lead time, and space requirement [97]. It is important to note that first pass correct output in lean performance measure in all stages to be the major motivator for implementing lean ergonomics approach in assembly process to saving in company cost not repeated the step. Ghosh, [98] was found in the research that the impact of the lean manufacturing practices on the manufacturing lead time, productivity, and first pass correct output is depends on the assembly process during lean performance measurement. Therefore, understanding the lean performance measurement in relation between lean ergonomics will help increasing the company's profits during assembly process [83]. Poor lean ergonomics factors can lead to the poor quality of the products, poor productivity and can cause the accidents due to the employees during works in assembly process and may effected to the lean performance measurement. That's mean, when the accident is happened; there are some problems to the company because the organisation management's responsibilities to reduce or eliminate the unsafe acts or unsafe conditions/ areas lead to accidents. The lean ergonomic concept should be applies to all employees that control/ works with machine, effective handling and avoiding from extremely focus to the implementing works on employees during working time in assembly process [99].

In all the studies reviewed, companies need to take seriously about this issues and also to the employees need have their own knowledge about lean ergonomics during in assembly process [53, 81]. Lean performance measure in lean ergonomics increased the company's efficiency and productivity profits, comfortable of employees and health, increase safety, prevent form accidents and errors, and also reduce the danger during the assembly process. Every single thing should be check and analyse from the starting process until the finish product and ready for the delivery to the customers to get better and correct body movement adopted by employees, body posture, used tools/ equipments, environmental physical factors that framing the works and also including the way of handling the ergonomics inventories, furniture and machinery, tooling, providing working and job methods, the ways of identification through property methodologies, awareness, training and information on the most method 
appropriately and technique to carry out the jobs or task [99]. The lean ergonomics knowledge should be applied for the working conditions, station to stations to carry out and perform the activities and operations in assembly process for the better lean performance measurement. In that ways, the company's objective and target to increase the profit at the same times to take care the employees working issues can be achieved.

\section{CONCLUSION}

This study has identified on determine the relationship of the lean manufacturing correlated to ergonomics by development of PDCA lean ergonomics conceptual framework approaches based literature review. The PDCA conceptual framework approach linked lean manufacturing and ergonomics in assembly process. The findings showed that lean manufacturing in the assembly process focused on eliminate waste that can give benefit to the company and cost reduction and also improvement on the process of the production system. Ergonomics focused on interactions of human and machine that can reduce employees physical stress for the employee's safety and comfortable during works for assembly process. The job design strategy is the standard of operational job task for assembly process to control and prevent on repetitive tasks. The job design and ergonomics risk factor may lead on the selections of lean tools and technique. The top management is responsible as checker or examiner and the way of assessment tools used that may assist in analysing risk factors during assembly process for human factor analysis. Lean performance measure is the point for the best solution chosen on the stages of the PDCA conceptual framework for lean ergonomics in assembly process. In relation based on PDCA conceptual framework, lean manufacturing is to eliminate waste (reduce cost) and ergonomics is to employees comfortable and safety is very important for the effective performance for the companies.

However, research on the lean ergonomics assembly process based on the development PDCA conceptual framework on lean ergonomics approach need to be continuously improvised for better relationship between employees and company. The main objective of the companies want to eliminate waste from lean manufacturing should synchronies with the nature of the employees conditions, comfortable and safety to prevent from defect on the system and employees physical stress during assembly process. The limitation in this review study is only limit and focus on the assembly process. Further study should be considering other type of manufacturing system to better understanding the relations between lean manufacturing and ergonomics. Besides, future studies might improve this conceptual framework by considering lean's seven wastes relations to the human factors. It is also suggested to work on the case study to illustrate the implementation of the proposed framework in the real system that may give big impact to the employee's conditions can be suggest.

\section{ACKNOWLEDGEMENT}

This research was co-funded under Ministry of Higher Education (MOHE) and Universiti Teknikal Malaysia Melaka (UTeM) under FRGS Grant (FRGS/1/2016/TK03/FTK-AMC/F00324).

\section{REFERENCES}

[1] J. P. Womack, D. Roos, and D. T. Jones, The Machine That Changed the World: The Massachusetts Institute of Technology 5-MillionDollar, 5-Year Report on the Future of the Automobile Industry. 1990.

[2] Yusup, M. Z., Wan Mahmood, W. H. and Salleh, M. R. "Implementation of lean practices based on Malaysian manufacturers' perspective: a confirmatory factor analysis", Int. J. Advanced Operations Management, vol. 8. no. 2, pp. 105-139. 2016.

[3] Yusup, M. Z., Wan Mahmood, W. H. and Salleh, M. R. "Basic Formation in Streamlining Lean Practices in Manufacturing Operations - A Review", International Journal of Advanced Operations Management, vol. 7, no. 4, pp. 255-273. 2015.

[4] P. Åhlström, "Sequences in the implementation of lean production," Eur. Manag. J., vol. 16, no. 3, pp. 327-334, 1998.

[5] L. Botti, C. Mora, and A. Regattieri, "Integrating ergonomics and lean manufacturing principles in a hybrid assembly line," Comput. Ind. Eng., 2017.

[6] Z. G. dos Santos, L. Vieira, and G. Balbinotti, "Lean Manufacturing and Ergonomic Working Conditions in the Automotive Industry," Procedia Manuf., vol. 3, no. Ahfe, pp. 5947-5954, 2015.

[7] R. Magnier-Watanabe, C. Benton, and D. Senoo, "A study of knowledge management enablers across 
countries," Knowl. Manag. Res. Pract., vol. 9, no. 1, pp. 17-28, 2011.

[8] S. M. Zahraee, "A survey on lean manufacturing implementation in a selected manufacturing industry in Iran," Int. J. Lean Six Sigma, vol. 7, no. 2, pp. 136-148, Jun. 2016.

[9] a. R. R. Rahani and M. Al-Ashraf, "Production Flow Analysis through Value Stream Mapping: A Lean Manufacturing Process Case Study," Procedia Eng., vol. 41, no. Iris, pp. 1727-1734, 2012.

[10]K. Demeter and Z. Matyusz, "The impact of lean practices on inventory turnover," in International Journal of Production Economics, 2011, vol. 133, no. 1 , pp. 154-163.

[11]M. Houshmand and B. Jamshidnezhad, "An extended model of design process of lean production systems by means of process variables," Robot. Comput. Integr. Manuf., vol. 22, no. 1, pp. 1-16, 2006.

[12]A. N. A. Wahab, M. Mukhtar, and R. Sulaiman, “A Conceptual Model of Lean Manufacturing Dimensions," Procedia Technol., vol. 11, no. Iceei, pp. 1292-1298, 2013.

[13]H. Hosseini Nasab, T. Aliheidari Bioki, and $\mathrm{H}$. Khademi Zare, "Finding a probabilistic approach to analyze lean manufacturing," J. Clean. Prod., vol. 29-30, pp. 73-81, 2012.

[14]K. Efthymiou, A. Pagoropoulos, N. Papakostas, D. Mourtzis, and G. Chryssolouris, "Manufacturing systems complexity review: Challenges and outlook," Procedia CIRP, vol. 3, no. 1, pp. 644-649, 2012.

[15] M. Z. Yusup, W. H. Wan Mahmood, M. R. Salleh, and A. S. Mohd Yusof. "Review The Influence Of Lean Tools And Its Performance Against The Index Of Manufacturing Sustainability." International Journal of Agile Systems and Management. vol. 8. no.2 pp. 116-131. 2015.

[16]K. O. Roper and D. C. Yeh, "Ergonomic solutions for an aging workforce," J. Facil. Manag., vol. 5, no. 3, pp. 172-178, 2007.

[17]N. A. Ansari and M. J. Sheikh, "Evaluation of work Posture by RULA and REBA : A Case Study," IOSR J. Mech. Civ. Eng., vol. 11, no. 4, pp. 18-23, 2014.

[18]V. Kamala, P. Malliga, and G. M. Priyanka, "Criteria based ergonomic assessment in a manufacturing industry," in IEEE International Conference on Industrial Engineering and Engineering Management, 2016, vol. 2016-Decem, pp. 238-242.
[19]S. Mattsson, P. Gullander, U. Harlin, G. Bäckstrand, A. Fasth, and A. Davidsson, "Testing complexity index - A method for measuring perceived production complexity," Procedia CIRP, vol. 3, no. 1, pp. 394-399, 2012.

[20] R. Usubamatov, A. Alsalam Alsalameh, R. Ahmad, and A. Rahman Riza, "Analysis of buffered assembly line productivity," Assem. Autom., vol. 34, no. 1, pp. 34-40, 2014.

[21]M. Groover, "Fundementals of Modern Manufacturing Materials,Processes and Systems," John Wiley Sons, p. 493, 2010.

[22]G. Boothroyd, P. Dewhurst, and W. A. Knight, Product design for manufacture and assembly, no. 74. 2011.

[23]D. E. Whitney, "Mechanical Assemblies: Their Design, Manufacture, and Role in Product Development," Advanced Manufacturing. p. 517, 2004.

[24]S. Lee, R. Suárez, and B. W. Choi, Frontiers of assembly and manufacturing: Selected papers from ISAM 2009. 2010.

[25]C. Ortiz, “All-out kaizen,” Industrial Engineer, vol. 38, no. 4. pp. 30-31, 2006.

[26]B. Villarreal and M. del R. Alanís, "A Simulation Approach to Improve Assembly Line Performance," Int. J. Ind. Eng., vol. 18, no. 6, pp. 283-290, 2011.

[27]E. Myler and G. Broadbent, "ISO 17799: Standard for Security., Inf. Manag. J., vol. 40, no. 6, pp. 4352, 2006.

[28]N. R, C and A. B, “A Generic Agent Framework to Support the InVarious Software Project Management Processes," Interdiscip. J. Information, Knowledge, Manag., vol. 2, 2007.

[29]IHI, "Going lean in health care," Innov. Ser., pp. 120, 2005.

[30]D. Allen, Getting Things Done. 2007.

[31]G. Miller, J. Pawloski, and C. Standridge, "A case study of lean, sustainable manufacturing," J. Ind. Eng. Manag., vol. 3, no. 1, pp. 11-32, 2010.

[32]K. B. Zandin, Maynard's Industrial Engineering Handbook, Fifth Edition, vol. 2567. 2004.

[33]M. Othman, N. Bhuiyan, and G. J. Gouw, "Integrating workers' differences into workforce planning," Comput. Ind. Eng., vol. 63, no. 4, pp. 1096-1106, 2012.

[34]Z. Xu, J. Ko, D. J. Cochran, and M.-C. Jung, "Design of assembly lines with the concurrent consideration of productivity and upper extremity 
musculoskeletal disorders using linear models," Comput. Ind. Eng., vol. 62, no. 2, pp. 431-441, 2012.

[35]J. Dul, H. De Vries, S. Verschoof, W. Eveleens, and A. Feilzer, "Combining economic and social goals in the design of production systems by using ergonomics standards," Computers and Industrial Engineering, vol. 47, no. 2-3. pp. 207-222, 2004.

[36]C. Lloyd and S. James, "Too much pressure? Retailer power and occupational health and safety in the food processing industry," Work. Employ. Soc., vol. 22, no. 4, pp. 713-730, 2008.

[37]A. Leroyer, H. Kraemer-Heriaud, L. Marescaux, and P. Frimat, "Prospective evaluation of the impact of organizational change on perceived stress and health in assembly-line workers in an automobile plant," Rev. d Epidemiol. Sante Publique, vol. 54, no. 1, pp. 15-25, 2006.

[38]J. Kester, "A lean look at ergonomics," Ind. Eng., vol. 45, no. 3, pp. 28-32, 2013.

[39]R. T. Smith, "Growing an ergonomics culture in manufacturing," Proc. Inst. Mech. Eng. Part B J. Eng. Manuf., vol. 217, no. 7, pp. 1027-1030, 2003.

[40]S. De Treville and J. Antonakis, "Could lean production job design be intrinsically motivating? Contextual, configurational, and levels-of-analysis issues," J. Oper. Manag., vol. 24, no. 2, pp. 99-123, 2006.

[41]M. Attaran and B. D. Wargo, "Succeeding with ergonomics in computerized offices," Work Study, vol. 48, no. 3, pp. 92-99, 1999.

[42]P. Cronin, F. Ryan, and M. Coughlan, "Undertaking a literature review: a step-by-step approach,” Br. J. Nurs., vol. 17, no. 1, pp. 38-43, 2008.

[43]S. Seuring and M. Müller, "From a literature review to a conceptual framework for sustainable supply chain management," J. Clean. Prod., vol. 16, no. 15, pp. 1699-1710, 2008.

[44]B. Kitchenham, "Procedures for performing systematic reviews," Keele, UK, Keele Univ., vol. 33, no. TR/SE-0401, p. 28, 2004.

[45]Y. Levy and T. J. Ellis, "A systems approach to conduct an effective literature review in support of information systems research," Informing Sci., vol. 9, pp. 181-211, 2006.

[46]H. J. Huang, "Job Rotation from the Employees' Point of View," Res. Pract. Hum. Resour. Manag., vol. 7, no. 1, pp. 75-85, 1999.

[47]M. C. O. Moreira and A. M. Costa, "Hybrid heuristics for planning job rotation schedules in assembly lines with heterogeneous workers," Int. J. Prod. Econ., vol. 141, no. 2, pp. 552-560, 2013.

[48]N. Azizi and M. Liang, "An integrated approach to worker assignment, workforce flexibility acquisition, and task rotation," J. Oper. Res. Soc., vol. 64, no. 2, pp. 260-275, 2012.

[49]A. Corominas, R. Pastor, and E. Rodríguez, "Rotational allocation of tasks to multifunctional workers in a service industry," Int. J. Prod. Econ., vol. 103, no. 1, pp. 3-9, 2006.

[50]A. Cristini and D. Pozzoli, "Workplace Practices and Firm Performance in Manufacturing: A Comparative Study of Italy and Britain," Int. J. Manpow., vol. 31, no. 7, pp. 818-842, 2010.

[51]P. C. Leider, J. S. Boschman, M. H. W. FringsDresen, and H. F. van der Molen, "Effects of job rotation on musculoskeletal complaints and related work exposures: a systematic literature review," Ergonomics, vol. 58, no. 1. pp. 18-32, 2015.

[52]M. L. C. Comper and R. S. Padula, "The effectiveness of job rotation to prevent work-related musculoskeletal disorders: protocol of a cluster randomized clinical trial," BMC Musculoskelet. Disord., vol. 15, no. 1, p. 170, 2014.

[53]W. P. Neumann, J. Winkel, L. Medbo, R. Magneberg, and S. E. Mathiassen, "Production system design elements influencing productivity and ergonomics," Int. J. Oper. Prod. Manag., vol. 26, no. 8, pp. 904-923, 2006.

[54]M. B. Frazer, R. W. Norman, R. P. Wells, and W. P. Neumann, "The effects of job rotation on the risk of reporting low back pain," Ergonomics, vol. 46, no. 9, pp. 904-919, 2003.

[55]P. C. Leider, J. S. Boschman, M. H. W. FringsDresen, and H. F. van der Molen, "When is job rotation perceived useful and easy to use to prevent work-related musculoskeletal complaints?," Appl. Ergon., vol. 51, pp. 205-210, 2015.

[56]L. B. d. M. Guimarães, M. J. Anzanello, and J. S. Renner, "A learning curve-based method to implement multifunctional work teams in the Brazilian footwear sector," Appl. Ergon., vol. 43, no. 3, pp. 541-547, 2012.

[57]J.-K. Park and S.-H. Jang, "Association between Upper Extremity Musculoskeletal Disorders and Psychosocial Factors at Work: A Review on the Job DCS Model's Perspective," Saf. Health Work, vol. 1, no. 1, pp. 37-42, 2010.

[58]S. J. Howarth, T. A. C. Beach, A. J. Pearson, and J. P. Callaghan, "Using sitting as a component of job 
rotation strategies: Are lifting/lowering kinetics and kinematics altered following prolonged sitting," Appl. Ergon., vol. 40, no. 3, pp. 433-439, 2009.

[59]M. Jorgensen, K. Davis, S. Kotowski, P. Aedla, and K. Dunning, "Characteristics of job rotation in the Midwest US manufacturing sector," Ergonomics, vol. 48, no. 15, pp. 1721-1733, 2005.

[60]C. Clegg and C. Spencer, "A circular and dynamic model of the process of job design," J. Occup. Organ. Psychol., vol. 80, no. 2, pp. 321-339, 2007.

[61]C. Wänström and L. Medbo, "The impact of materials feeding design on assembly process performance," J. Manuf. Technol. Manag., vol. 20, pp. 30-51, 2009.

[62]P. Jonsson and S. Mattsson, "The implications of fit between planning environments and manufacturing planning and control methods," Int. J. Oper. Prod. Manag., vol. 23, no. 8, pp. 872-900, 2003.

[63]A. Howard, A. Kochhar, and J. Dilworth, "A rulebase for the specification of manufacturing planning and control system activities," Int. J. Oper. Prod. Manag., vol. 22, no. 1, pp. 7-29, 2002.

[64]P. Bicheno, John, "Value Stream Mapping," New Lean Toolbox Towar. Fast Flex. Flow, p. 35, 2004.

[65]J. E. Fernandez, "Ergonomics in the workplace," vol. 13, no. 4, pp. 20-27, 2007.

[66]P. G. Dempsey and L. Hashemi, "Analysis of workers' compensation claims associated with manual materials handling," Ergonomics, vol. 42, no. 1, pp. 183-195, 1999.

[67]S. O. Jekayinfa, "Ergonomic Evaluation and Energy Requirements of Bread-baking Operations in South Western Nigeria,” Agric. Eng. Int., vol. IX, pp. 112, 2007.

[68]C. C. and B. H. Kleiner and Webster's, "NEW DEVELOPMENTS IN ERGONOMICS," pp. 2-7, 1993.

[69]R. S. Padula, M. L. C. Comper, E. H. Sparer, and J. T. Dennerlein, "Job rotation designed to prevent musculoskeletal disorders and control risk in manufacturing industries: A systematic review," Appl. Ergon., vol. 58, pp. 386-397, 2017.

[70]R. H. Ansah and S. Sorooshian, "Effect of lean tools to control external environment risks of construction projects," Sustain. Cities Soc., vol. 32, no. April, pp. 348-356, 2017.

[71]W. M. N. Wan Muhammad, Z. Ismail, and A. E. Hashim, "Exploring lean construction components for Malaysian construction industry," in BEIAC
2013 - 2013 IEEE Business Engineering and Industrial Applications Colloquium, 2013, pp. 1-6.

[72]R. F. Aziz and S. M. Hafez, "Applying lean thinking in construction and performance improvement," Alexandria Eng. J., vol. 52, no. 4, pp. 679-695, 2013.

[73]M. A. Marhani, A. Jaapar, N. A. A. Bari, and M. Zawawi, "Sustainability Through Lean Construction Approach: A Literature Review," Procedia - Soc. Behav. Sci., vol. 101, pp. 90-99, 2013.

[74]H. H. Bashford, K. D. Walsh, and A. Sawhney, "Production System Loading-Cycle Time Relationship in Residential Construction," J. Constr. Eng. Manag., vol. 131, no. 1, pp. 15-22, 2005.

[75]S. a Schweikhart and A. E. Dembe, "The applicability of Lean and Six Sigma techniques to clinical and translational research.," J. Investig. Med., vol. 57, no. 7, pp. 748-55, 2009.

[76]H. A. Richard, S. Sorooshian, and S. Bin Mustafa, "Analytic Hierarchy Process Decision Making Algorithm," Glob. J. Pure Appl. Math., vol. 11, no. 4, pp. 2403-2410, 2015.

[77]A. Anvari, N. Zulkifli, S. Sorooshian, and O. Boyerhassani, "An integrated design methodology based on the use of group AHP-DEA approach for measuring lean tools efficiency with undesirable output," Int. J. Adv. Manuf. Technol., vol. 70, no. 912, pp. 2169-2186, 2014.

[78]B. H. and Koay and S. Sorooshian, "Study on Impact of Lean Six Sigma," J. Manag. Sci., vol. 3, no. 4, pp. 91-96, 2013.

[79]H. Abdul Rahman, C. Wang, and I. Y. W. Lim, "Waste processing framework for non-value-adding activities using lean construction," J. Front. Constr. ..., vol. 1, pp. 8-13, 2012.

[80]L. Zhang and X. Chen, "Role of Lean Tools in Supporting Knowledge Creation and Performance in Lean Construction," Procedia Eng., vol. 145, pp. 1267-1274, 2016.

[81]H. J. C. G. Coury, J. Alfredo Léo, and S. Kumar, "Effects of progressive levels of industrial automation on force and repetitive movements of the wrist,” Int. J. Ind. Ergon., vol. 25, no. 6, pp. 587595, 2000.

[82]A. Al-Zuheri, L. Luong, and K. Xing, "Developing a multi-objective genetic optimisation approach for an operational design of a manual mixed-model assembly line with walking workers," J. Intell. Manuf., vol. 27, no. 5, pp. 1049-1065, 2016. 
[83]L. Vieira, G. Balbinotti, A. Varasquin, and L. Gontijo, "Ergonomics and Kaizen as strategies for competitiveness: A theoretical and practical in an automotive industry," in Work, 2012, vol. 41, no. SUPPL.1, pp. 1756-1762.

[84]A. Abdelhadi, "Investigating emergency room service quality using lean manufacturing," Int. J. Health Care Qual. Assur., vol. 28, no. 5, pp. 510519, 2015.

[85]R. A. Hamid, "Factor influencing the success of lean services implementation: conceptual framework," Int. Conf. Bus. Econ. Res. Proceeding, pp. 14961509, 2011.

[86]M. Alefari, K. Salonitis, and Y. Xu, "The Role of Leadership in Implementing Lean Manufacturing," Procedia CIRP, vol. 63, pp. 756-761, 2017.

[87]K. Salonitis and C. Tsinopoulos, "Drivers and Barriers of Lean Implementation in the Greek Manufacturing Sector," Procedia CIRP, vol. 57, pp. 189-194, 2016.

[88]S. Zargun and A. Al-Ashaab, "Critical Success Factors for Lean Manufacturing: A Systematic Literature Review an International Comparison between Developing and Developed Countries," Adv. Mater. Res., vol. 845, no. May 2016, pp. 668681, Dec. 2013.

[89]F. Pakdil and K. M. Leonard, "Implementing and sustaining lean processes: the dilemma of societal culture effects," Int. J. Prod. Res., vol. 55, no. 3, pp. 700-717, 2017.

[90]A. Abdelhadi and M. Shakoor, "Studying the efficiency of inpatient and outpatient pharmacies using lean manufacturing," Leadersh. Heal. Serv., vol. 27, no. 3, pp. 255-267, 2014.
[91]F. Aqlan, S. S. Lam, S. Ramakrishnan, and W. Boldrin, "Integrating lean and ergonomics to improve internal transportation in a manufacturing environment," in IIE Annual Conference and Expo 2014, 2014, pp. 3096-3101.

[92]L. Botti, C. Mora, and A. Regattieri, "Integrating ergonomics and lean manufacturing principles in a hybrid assembly line," Comput. Ind. Eng., vol. 111, pp. 481-491, 2017.

[93]B. G. Dillard, T. Frazier, and T. F. Schwager, "Ergonomic equipment investments: benefits to apparel manufacturers," Int. J. Cloth. Sci. Technol., vol. 9, no. 4, pp. 285-300, 1997.

[94]J. Bartnicka, "Knowledge-based ergonomic assessment of working conditions in surgical ward A case study," Saf. Sci., vol. 71, no. PB, pp. 178$188,2015$.

[95]M. Khairul et al., "Comparative Study of Rapid Upper Limb Assessment ( RULA ) and Rapid Entire Body Assessment ( REBA ) Between Conventional and Machine Assisted Napier Grass Harvest Works," vol. 786, no. Icadme, pp. 30-31, 2015.

[96]R. Shah, S. M. Goldstein, B. T. Unger, and T. D. Henry, "Explaining Anomalous High Performance in a Health Care Supply Chain*," Decis. Sci., vol. 39, no. 4, pp. 759-789, 2008.

[97]R. Shah and P. T. Ward, "Lean manufacturing: Context, practice bundles, and performance," J. Oper. Manag., vol. 21, no. 2, pp. 129-149, 2003.

[98]M. Ghosh, "Lean manufacturing performance in Indian manufacturing plants," J. Manuf. Technol. Manag., vol. 24, no. 1, pp. 113-122, 2012.

[99]B. Cirjaliu and A. Draghici, "Ergonomic Issues in Lean Manufacturing," Procedia - Soc. Behav. Sci., vol. 221, pp. 105-110, 2016. 